\title{
Biodiversity law could stymie research
}

Tighter rules on accessing and developing genetic resources may be counterproductive for conservation.

Scientists who study the world's biodiversity are facing a dilemma: proposals to regulate access to the riches of ecological hotspots may hamper the research needed to monitor these areas.

The warning comes as signatories to the Convention on Biological Diversity (CBD) begin negotiating ways to strengthen the treaty's legal framework and goals, which include conserving biodiversity and promoting the sustainable use of natural resources (see 'Key questions'). A crucial part of that effort, discussed last week at meeting in Montreal, Canada, is the reform that is generally regarded as the least effective aspect of the CBD: deciding who can exploit valuable genetic resources, such as plants that produce potential pharmaceuticals, and who should benefit financially.

Many developing countries complain that this aspect of the CBD relies on voluntary guidelines, rather than clear international legislation. This makes it difficult to police how genetic resources are used, and to ensure that countries are paid fairly if commercial products are developed from their resources. Moreover, national regulations governing access and benefit sharing can vary enormously between countries, confusing both commercial and non-commercial researchers.

The negotiators aim to produce a legally binding framework that resolves all these problems, which will be considered for adoption under the $\mathrm{CBD}$ at a meeting of the convention's signatory countries in October in Nagoya, Japan.

But tougher regulation could come with a cost, warns David Schindel, an invertebrate

\section{Key questions}

Five critical points for discussion as negotiators aim to strengthen the Convention on Biological Diversity:

- Is an ambitious long-term vision of halting all extinctions by 2050 realistic?

- Should action plans and targets to cut biodiversity loss be set at the national or international level?

- Can agricultural and other subsidies that

are harmful to biodiversity be eliminated?

- Can every species facing extinction

be allocated at least one protected area

supporting a viable population?

- What is the best way of ensuring

sustainable management of agriculture,

forestry and aquaculture?

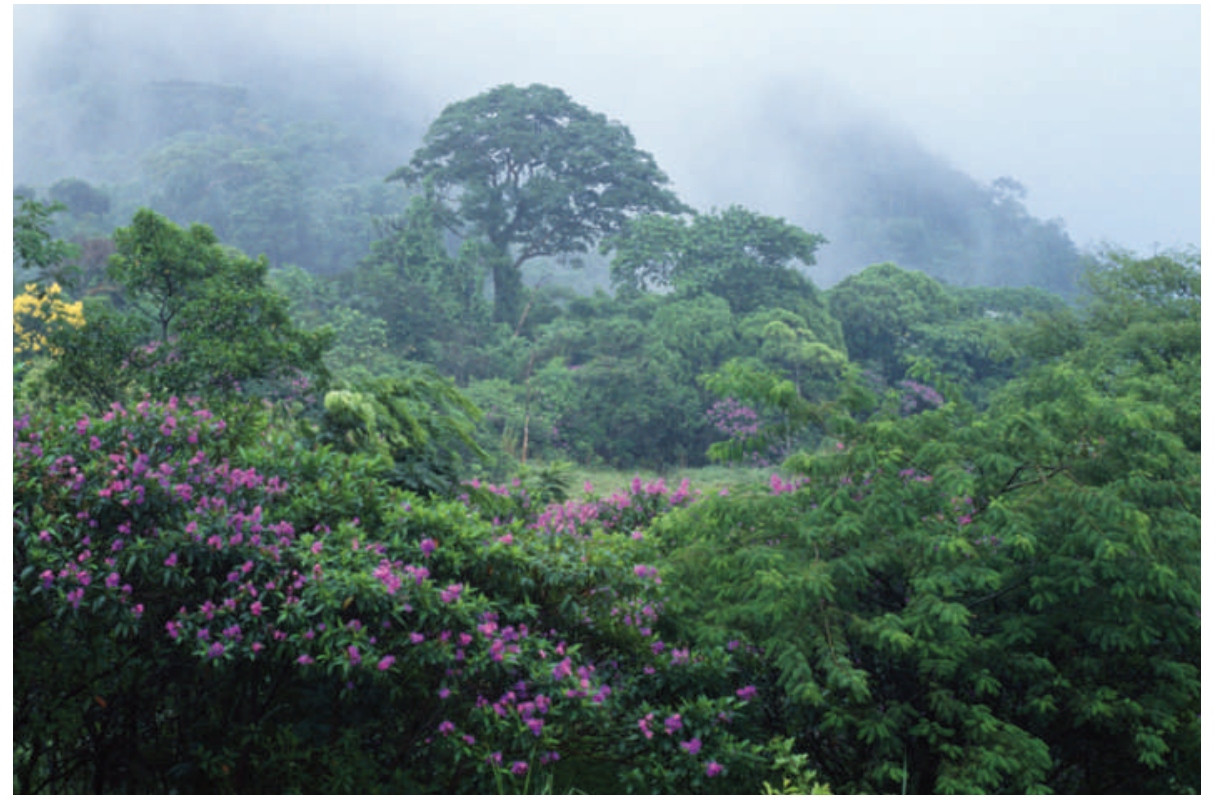

Efforts to regulate access to natural resources in Brazil have delayed research projects by years.

palaeontologist and executive secretary of the Consortium for the Barcode of Life, an international initiative to identify species using short genetic sequences, based at the Smithsonian Institution in Washington DC. "We are very concerned that it will become more restrictive," he says. In some cases, it can already take at least two years and reams of paperwork to agree the terms on which research can be conducted, specimens exported and profits shared. "You could go through a field season collecting specimens and then the
"If we get agreement, it will be a major breakthrough."
India, still have highly restrictive regimes, says Schindel. He hopes that the new CBD framework will clarify the situation, although some experts say that defining commercial research will not be easy - it is increasingly common for academic scientists to make patent applications based on their research, for example.

Ahmed Djoghlaf, executive secretary of the CBD, points out that an improved international framework should also benefit companies, giving them more confidence to invest the time and money required to develop to hold on to them because you don't have the right permission," he says. "The specimens sit on a dock, rot and are lost."

David Oren, coordinator of biodiversity in the ecosystems management office of Brazil's Ministry of Science and Technology, agrees that the framework must strike a balance between protecting a nation's intellectual property and not impeding research. He says that access and benefits legislation introduced by Brazil in 2002 "essentially stopped" research on biodiversity in the country, as it restricted the exchange of specimens between institutions. The rules have since been relaxed to make a clear distinction between basic and commercial research, making it easier for academics to study biodiversity in Brazil, but many other countries, including

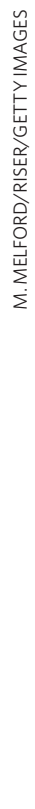

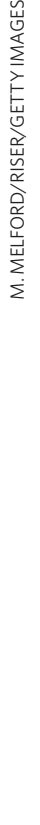

